\title{
INTERNAL CAROTID ARTERY CLASSIFICATION SYSTEMS
}

Rafał CHMIELEWSKI', Bogdan CISZEK²

1 Department of Otolaryngology, Military Institute of Aviation Medicine, Warsaw, Poland 2 Department of Descriptive and Clinical Anatomy, Centre for Biostructure Research, Warsaw Medical University, Warsaw, Poland

Source of support: Own sources

Author's address: R. Chmielewski, Military Institute of Aviation Medicine, Krasińskiego 54/56 Street, 01-755 Warsaw, Poland, e-mail: rafalchmielewski@gmail.com

Purpose: Development of medicine and anatomical knowledge in particular attempt to produce a detailed description of the human body. The ultimate goal is a better preparation for the necessary surgical procedures in the anatomical area of interest. Research on the anatomy and topography of the internal carotid artery (ICA) and its following classification systems mirrored this progress and the technical and technological discoveries in the area of imaging and treatment of the ICA pathologies.

Methods: A review of the literature was performed using the MEDLINE database and other offline bibliographic sources. The search included only human studies between 1938 and 2017. All open dissection, endoscopic and angiographic studies were included.

Results: We present the evolution of the internal carotid artery classification systems starting from the classic work of Willis. This development follows the needs for adjusting the ICA divisions to clinical applications, both radiologic in classic angiographic diagnosis and therapeutic through an extensive skull base surgical approaches to more and more popular endoscopic transnasal and other ICA procedures.

Conclusions: As described above, the ICA anatomy and topography still undergoes an extensive variety of research projects which put more and more light on this clinically important and very interesting vessel.

Keywords: internal carotid artery, ICA, ICA classification system, ICA radiologic evaluation, ICA surgical approaches

Figures: 3 • Tables: 3 • References: 29 • Full-text PDF: http://www.pjambp.com • Copyright @ 2018 Polish Aviation Medicine Society, ul. Krasińskiego 54/56, 01-755 Warsaw, license WIML • Indexation: Index Copernicus, Polish Ministry of Science and Higher Education 
Tab. 1. Embryological classification of the ICA by segments according to Lasjaunias and Berenstein [17].

\begin{tabular}{|c|c|c|}
\hline Segment & Name & Embryological origin \\
\hline 1 & Cervical & Third aortic arch \\
\hline 2 & Ascending intrapetrous & Dorsal aorta between second and third aortic arches \\
\hline 3 & Horizontal intrapetrous & Dorsal aorta between first and second aortic arches \\
\hline 4 & Ascending in the foramen lacerum and cavernous sinus & Dorsal aorta between first aortic arch and primitive maxillary artery \\
\hline 5 & Horizontal of carotid siphon & Dorsal aorta between primitive maxillary artery and dorsal ophthalmic artery \\
\hline 6 & Clinoidal & Dorsal aorta between primitive maxillary artery and dorsal ophthalmic artery \\
\hline 7 & Terminal & Distal to ventral ophthalmic artery \\
\hline
\end{tabular}

\section{INTRODUCTION}

Development of medicine and anatomical knowledge in particular attempt to produce a detailed description of the human body. The ultimate goal is a better preparation for the necessary surgical procedures in the anatomical area of interest. Research on the anatomy and topography of the internal carotid artery (ICA) and its following classification systems mirrored this progress and the technical and technological discoveries in the area of imaging and treatment of the ICA pathologies. Current anatomical knowledge on the ICA anatomy can provide better diagnosis and treatment of its pathologies, which can be even more crucial in case of the military and civil flying crew.

\section{METHODS}

A review of the literature was performed using the MEDLINE database and other offline bibliographic sources. The search included only human studies between 1938 and 2020. All open dissection, endoscopic and angiographic studies were included.

\section{RESULTS AND DISCUSSION}

In 1938, Fischer described angiographic pictures of the ICA, anterior and middle cerebral arteries dislocations caused by the intracranial pathologies [9]. He is known from the first modern ICA classification, though Willis described four segments of the ICA in 17th century [28]. Fisher's ICA segments were numbered starting from the terminal end in the opposite direction to blood flow. The study was based on the plain $\mathrm{x}$-ray angiograms of the cerebral arteries with no topographic details described. In 1993 Fukushima in personal communication tried to correct Fischer's classifications by adding the $\mathrm{C} 6$ (petrous) segment, starting in the entrance of the carotid canal and finishing on the lateral margin of the trigeminal (Gasserian) ganglion.
Gibo et al. in 1981 made significant changes to the ICA classification. They described the entire ICA from the carotid bifurcation to its terminal branching, numbering the segments in the direction of blood flow. In this classification the clinoid segment was omitted and the distal part of the petrous segment was incorporated in the cavernous one [10].

Lasjaunias and Berenstein added the clinoid segment to the Gibo et al. classification describing the entire ICA from the carotid bifurcation to its end, numbering the segments in the direction of blood flow, but the division was based on the vascular embryological development [17]. It is useful in understanding e.g. segmental hypoplasia of the vessel or persisted primitive ICA branches but it is less applicable to most clinical and surgical conditions as the topographical relationships are not included - table 1 .

Other authors concentrated on anatomical relationships of the ICA course and subdivision of the particular segments [6] - division of the cavernous segment (table 2) or describing main arterial loops of the intracranial ICA [18] - starting from the posterior through lateral, medial and finishing with the anterior loop, along the vessel course and blood flow. The disadvantages of those attempts are selective descriptions of the ICA parts and possibly misleading variations of the vessel tortuosity e.g. due to hypertension.

Tab. 2. Division of the cavernous segment of the ICA by Debrun et al. [6].

\begin{tabular}{cl}
\hline Segment & \multicolumn{1}{c}{ Name } \\
\hline 1 & Anterior ascending \\
\hline 2 & Junction of 1 and 3 \\
\hline 3 & Horizontal \\
\hline 4 & Junction of 3 and 5 \\
\hline 5 & Posterior ascending \\
\hline
\end{tabular}

Inoue et al. divided the ICA into 5 segments posterior vertical, posterior bend, horizontal, 

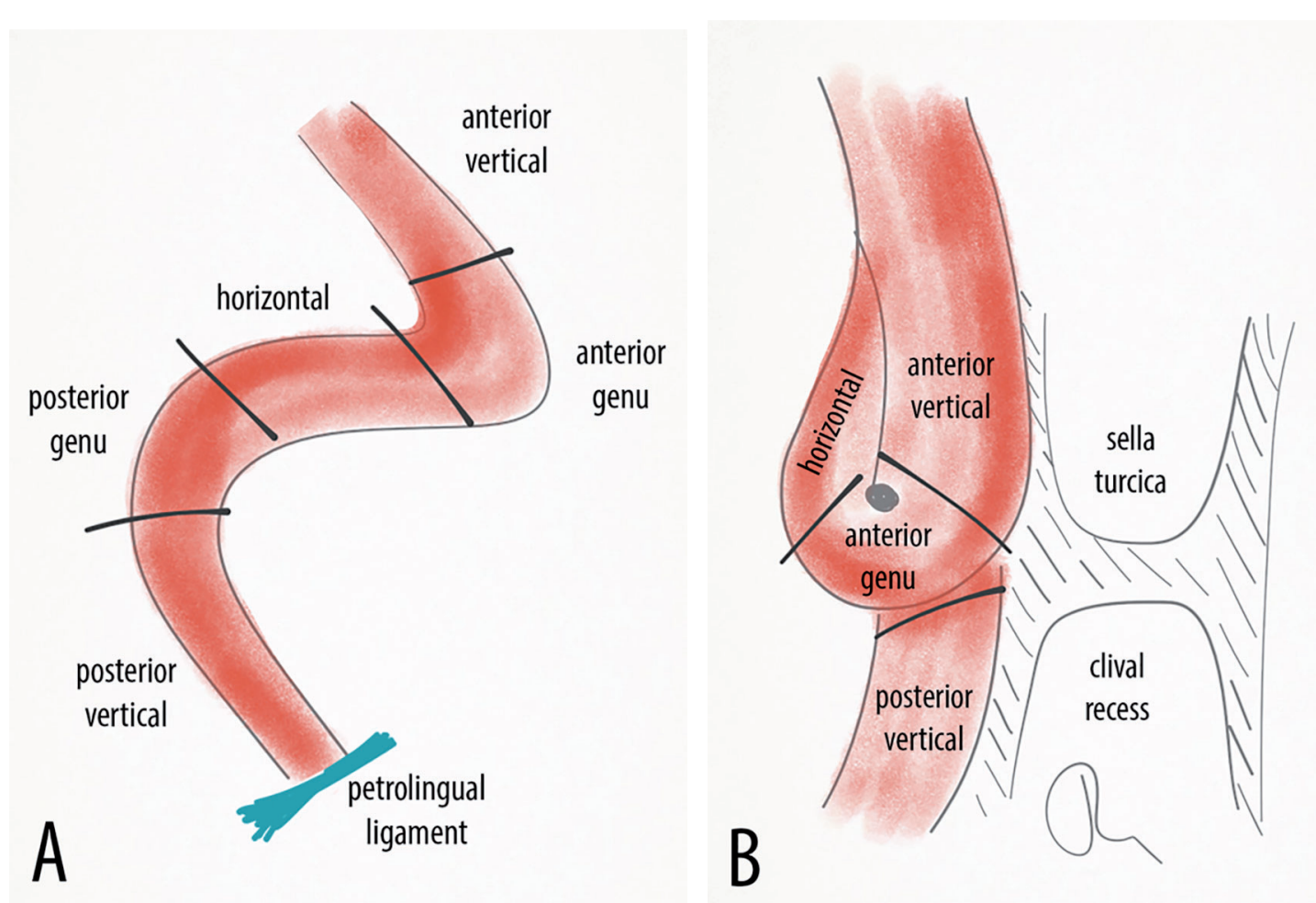

Fig. 1. Cavernous segment of the ICA with its subdivisions by Inoue et al. [14].

anterior bend and anterior vertical - figure 1. The terminal portion of the anterior vertical segment, running medially to the anterior clinoid process, is named the clinoid segment [14]. A discrepancy is noted in their publication - "The internal carotid artery exits the foramen lacerum and enters the posterior-inferior part of the cavernous sinus". I is known, it is very unusual for the ICA to enter the skull through the foramen lacerum. The artery crosses the foramen from above on its way to the cavernous sinus.

Bouthillier, van Loveren and Keller developed numerical classification of the entire course of the ICA in the direction of blood flow with respect to the topography of the adjacent anatomical compartments in 1996 [3]. Authors emphasized neurosurgical practice usefulness of their classification and that it continuous previous nomenclature tradition (table 3).

Bouthillier et al. introduced the lacerum segment (C3), between the petrous and cavernous parts, included in C5 segment in Fischer's classification. It became important with the development of transfacial surgical approaches or opening of the Meckel's cave. Authors redefined lower border of the cavernous (C4) segment as the upper margin of the petrolingual ligament, while Fischer put it on level of the medial loop of the ICA. Cli- noid (C5) segment, corresponding to Fisher's C3, was named "the knee of the ICA" and remained omitted in further studies until cavernous sinus surgery and e.g. ophthalmic ICA segment aneurysm approaches have evolved.

Alfieri and Jho studied ten latex-injected ICA in their cavernous segments with the 0,30 , and 70-degree endoscopic lenses. Authors divided the paraclival segment into the proximal lacerum and distal trigeminal parts with the entrance to the cavernous sinus as a border. They pointed out that the petrolingual ligament located behind the ICA is not a useful landmark from the anterior

Tab. 3. Anatomical and topographical classification of the ICA segments by Bouthillier et al. [3].

\begin{tabular}{|c|c|}
\hline Segment & Name \\
\hline C1 & Cervical \\
\hline C2 & Petrous \\
\hline C3 & Lacerum \\
\hline \multirow[t]{5}{*}{ C4 } & Cavernous: \\
\hline & · Vertical \\
\hline & - Posterior bend \\
\hline & - Horizontal \\
\hline & - Anterior bend \\
\hline C5 & Clinoid \\
\hline C6 & Ophthalmic \\
\hline C7 & Communicating \\
\hline
\end{tabular}




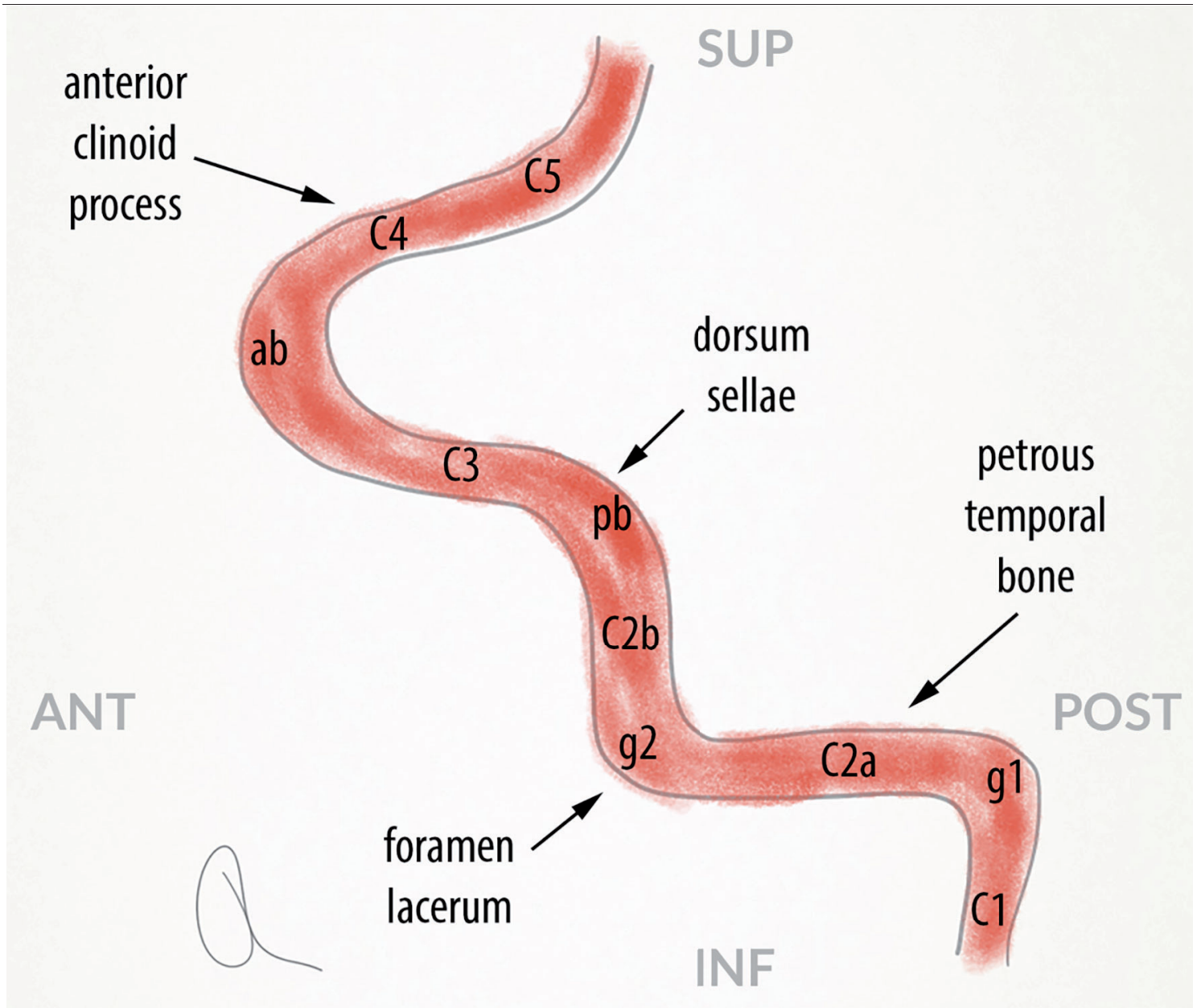

Fig. 2. ICA classification by Herzallah and Casiano [12] - lateral view with the main topographic landmarks. $\mathrm{C}_{1}$ - cervical segment, g1 - first or posterior genu, $\mathrm{C}_{2} \mathrm{a}$ - petrous segment (with g1), g2 - second or anterior genu, $\mathrm{C}_{2} \mathrm{~b}-$ lacerum segment, pb-posterior bend, $C_{3}$ - cavernous segment, ab - anterior bend, $C_{4}$ - clinoid segment, $C_{5}$ - cisternal segment, SUP - superior, INF - inferior, ANT - anterior POST - posterior.

endoscopic standpoint. Parasellar segment was divided into 4 parts starting proximally from hidden, inferior horizontal, anterior vertical and superior horizontal. Hidden part corresponds to the posterior knee of the cavernous ICA, occupies the space behind the sella, being invisible endoscopically. Inferior horizontal part located in front of the former, seems to be shorter in an endoscopic perspective. Anterior vertical part is most prominent, bulging laterally to the front face of the sella. Last part - superior horizontal, corresponds to the clinoid and subarachnoid segments. In the ipsilateral zero-degree angle transnasal endoscopic perspective, parasellar segment is straight and flattened while in the contralateral angled transseptal or transethmoid perspective it looks like the letter "C" [1].

Ziyal et al. developed a new ICA classification based on the dissection of 15 human cadaveric heads and 5 skulls. They proposed a revision of the Bouthillier's classification into 5 segments C1 - cervical, C2 - petrous, C3 - cavernous, C4 - clinoid and C5 - cisternal. Lacerum segment was excluded by the authors as anatomically and clinically unnecessary. Petrolingual ligament was not considered as a reference point for the lacerum foramen, which in no case contained the ICA within it. The lacerum segment should be included in the cavernous segment as the petrolingual ligament is indeed a continuation of the fibrous capsule of the Meckel's cave. Ziyal et al. use the term "trigeminal part" due to its close relationship with the trigeminal nerve, but they do not include this segment in the final version of their classification. Authors also point out that Bouthillier described the clinoid segment as an extracavernous while it is surrounded by the cavernous venous plexus projection laterally. In this case it should be considered paracavernous. The cisternal (C5) segment should not be further divided into the ophthalmic and communicating parts as the variability of the branching points is significant and does not make a reliable anatomical points [29]. 
Herzallah and Casiano on the material of 20 cadaveric specimens conducted an endoscopic dissection. Authors divided the ICA into the following segments starting from the CCA bifurcation: cervical (C1) - to the carotid canal entrance, petrous (C2a) inside the carotid canal with the first or posterior knee (g1), lacerum (C2b) starting with the second or anterior knee (g2), passing over the foramen lacerum, cavernous (C3) described below, clinoid (C4) medial to the anterior clinoid process and cisternal or subarachnoid (C5), immediately before the ICA bifurcation - figure 2 [12].

Cavernous segment of the ICA starts at the level of the upper margin of the petrolingual ligament. Anterior transnasal endoscopic approach allows for visualization of two distinct subsegments - paraclival and parasellar, particularly in a well pneumatized sphenoid sinus. Lower part of the paraclival and upper part of the parasellar segments are extracavernous, still being covered by the dura. Paraclival segment corresponds to the vertical part of the cavernous ICA and lateral margin of the clival recess of the sphenoid sinus endoscopically. At certain level the ICA bends forward creating the posterior genu of the cavernous segment, next it runs as a horizontal segment to bend superiorly in an anterior genu below the anterior clinoid process. Anterior vertical segment of the cavernous ICA is also named clinoid, infraclinoid or paraclinoid. Parasellar segment coursing on the side of the pituitary gland, frequently makes a significant sinus wall protrusion at that level. It corresponds to a distal horizontal, anterior genu and clinoid cavernous IC parts.

Herzallah and Casiano classified the cavernous segment of the ICA into the paraclival, posterior bend and parasellar segments. Topographically paraclival segment was further divided into the petroclival and trigeminal parts. Posterior bend is supporting the pituitary gland at the level of the floor of sella turcica. Parasellar segment is composed of the inferior horizontal part, running anteriorly and laterally with the abducent nerve, the anterior vertical part, being related to the oculomotor nerve, and the superior horizontal one. In the last one authors distinguish the clinoid part, a basis for the optic strut triangle, and the cisternal part coursing posteriorly and superiorly to the ICA bifurcation into the anterior and posterior cerebral arteries. Herzallah and Casiano point out the practical endoscopic usability of their classification and specific visualization the ICA segments due to the angle of the optics used. Additionally authors describe three types of the posterior bend angle - la - straight angle between the paraclival and para- sellar segments, lb - obtuse angle with the parasellar segment running obliquely anteriorly and superiorly what creates a significant surgical damage hazard and II - with formation of a " $\mathrm{C}$ " shaped posterior cavernous loop located on the side of the sella turcica, above the petrous apex and narrowing a surgical corridor medially to the ICA - figure 3 .

Castelnuovo, Dallan and Tschabitscher in their monograph "Surgical anatomy of the internal carotid artery" admitted that the cervical segment boundaries with the lower (carotid bifurcation) and upper (carotid foramen) are widely accepted. It is traditionally divided into a proximal and distal part, the demarcation point being the posterior belly of the digastric muscle. The next petrous segment is entirely extradural and intraosseous, extending from the carotid foramen to the superior margin of the petrolingual ligament. Authors name the posterior genu of the ICA as it bends anteriorly, the horizontal part and the anterior genu as it bends superiorly above the foramen lacerum. Although they do not classify this part as a separate segment of the ICA, they acknowledge the authors who do - Bouthillier et al. - the lacerum segment [3] and Herzallah and Casiano - supralacerum segment [12]. Above the petrolingual ligament the cavernous segment starts, which can be divided into the paraclival and parasellar parts from the anterior endoscopic viewpoint. Authors support the cavernous segment division proposed by Inoue et al. into 5 parts - posterior vertical, posterior bend, horizontal, anterior bend and anterior vertical [14]. They stress that the posterior bend varies significantly and can bulge upward to press against the cavernous sinus roof dura, just lateral to the posterior clinoid process. The last part of the cavernous segment, the anterior vertical, named by Bouthillier et al. "the clinoid" was not separated from the former from an endoscopic perspective although it is not entirely intracavernous. Castelnuovo et al. do not support further divisions of the cavernous segment other that into the paraclival and parasellar parts as those are producing endoscopically visible prominences in the sphenoidal window. Lastly, there is a cisternal segment extending from the distal dural ring to the carotid bifurcation [5].

Bouthillier's successors, in 2014 question whether his classification can be successfully applied to the skull base endoscopic approaches. Endoscopic two-dimensional, flat and magnified visualization is significantly different from a microscopic three-dimensional open surgical access [7]. Authors made a high-resolution CT scan of 5 human cadaveric heads, followed by the trans- 


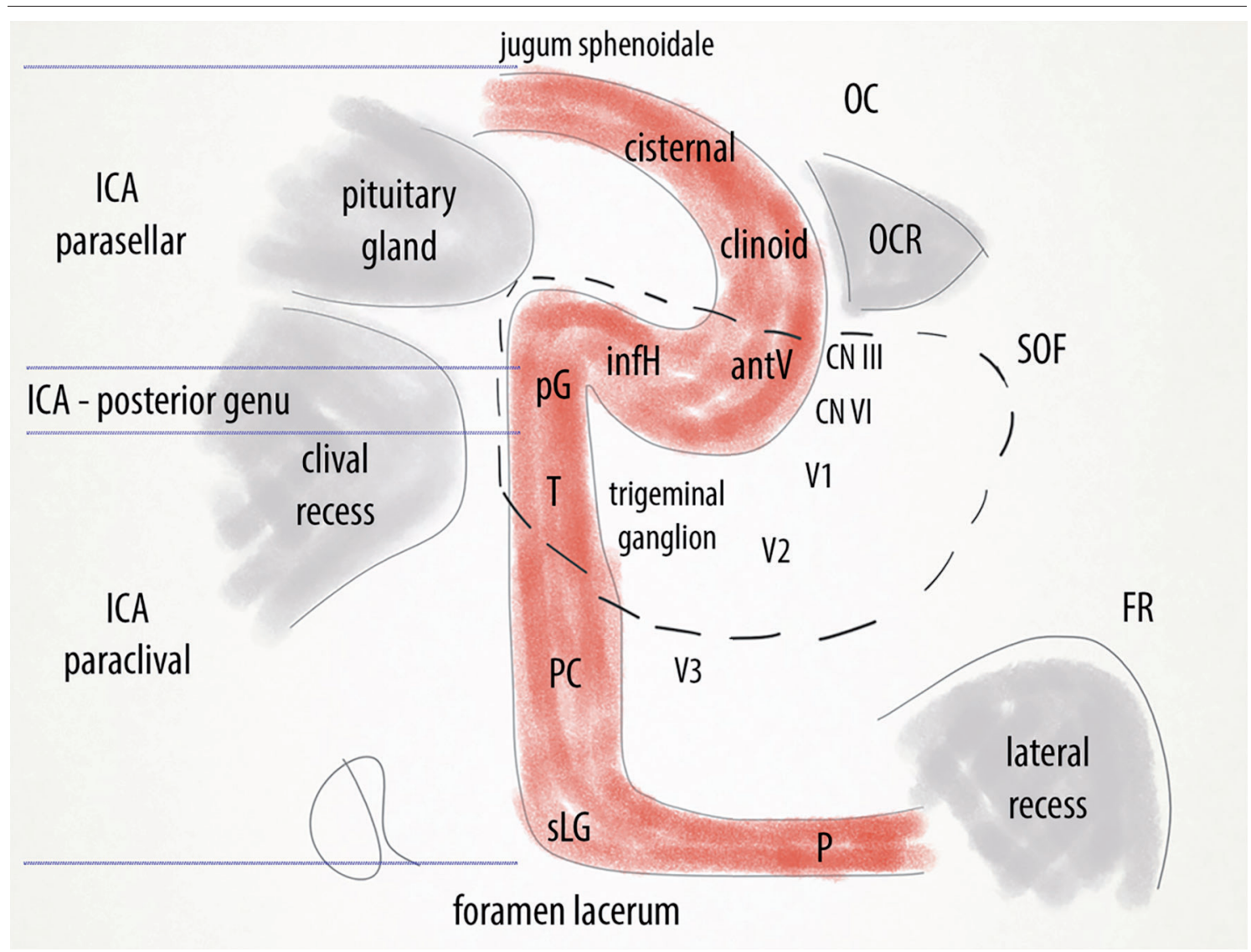

Fig. 3. Left ICA in the sphenoid sinus anterior endoscopic view by Herzallah and Casiano [12].

Cavernous sinus encircled with a dashed line; OC - optic canal, ICA - internal carotid artery, OCR - optico-carotid recess, SOF - superior orbital fissure, $F R$ - foramen rotundum, $\mathrm{P}$ - petrous segment, sLG - supralacerum genu, $\mathrm{PC}$ - paraclival segment, $\mathrm{T}$ - trigeminal part, $\mathrm{pG}$ - posterior genu, infH - inferior horizontal segment, antV - anterior vertical segment, CN III-oculomotor nerve, CN IV - trochlear nerve, V1 - ophthalmic division of the trigeminal nerve, $\mathrm{V}_{2}$ - maxillary division of the trigeminal nerve, $\mathrm{V}_{3}$-mandibular division of the trigeminal nerve.

nasal endoscopic dissection and bilateral open fronto-temporal craniotomies. In results they renamed four Bouthillier's loops - posterior, lateral, medial and anterior with four bends - C2, C3-C4, C4 and C4-C5, which according to authors, better describe direction of the vessel course. C2 bend changes the course of the petrous segment from vertical to horizontal, C3-C4 between the lacerum and cavernous segments switches the direction from antero-medial to superior, finally $\mathrm{C} 4$ bend, positioned on the side of the posterior clinoid process, to antero/antero-lateral course. The last two ICA segments and bends are essential in understanding anatomy of the vessel as it differs in endoscopic and open access perspectives. Paraclival segment is short in the lateral intracranial view whereas in the endoscopic perspective it's long and straight. Authors do not support the "paraclival segment" name because it does not go parallel to the clivus and its endoscopic picture is flattened and distorted. It corresponds to the upper lacerum segment (C3) and the lower posterior ascending part of the cavernous segment (C4). Last $\mathrm{C} 4-\mathrm{C} 5$ bend directs the ICA from horizon- tal to anterior direction, terminating in the distal dural ring, where the intradural part begins. This portion was previously called "parasellar" as goes on the side of sella turcica. Cavernous ICA subdivisions were named after Debrun's classification [6]. In summary, the authors find Bouthillier's classification fully valid and accurate for both the endoscopic and open transcranial surgical approaches. Replacing the names of the loops to bends seem not to be justified with their work. It does not clarify Bouthillier's classification and does not add value to current anatomical nomenclature.

Labib et al. tried to develop the comprehensive ICA classification based on key anatomical landmarks, independent on the vessel's geometry or the degree of neighboring sinus pneumatisation [16]. The goal was to serve as a practical orientation guide to the ventral transnasal endoscopic approach. Authors distinguished 6 segments of the ICA - parapharyngeal (from the common carotid bifurcation to the carotid canal entrance), petrous (in the carotid canal up to the posterolateral aspect of the foramen lacerum), paraclival (to the superomedial aspect of the petrous apex), para- 
sellar (to the proximal dural ring), paraclinoid (to the distal dural ring) and intradural (to the origin of the ICA terminal branches). Labib et al. refers to the paper by Alfieri et al. [1] as "the only meaningful attempt to classify the segments of the ICA from an endoscopic endonasal perspective", though the limitations are also mentioned. Firstly it excludes the ICA segments proximal to the foramen lacerum, being approached endoscopically more and more commonly in recent years. Secondly, it relies on the variable sphenoid sinus pneumatisation. Thirdly, it describes certain segments of the artery on the basis of its geometry which may be altered by the tumor growth or by the endoscopic perception and lastly, it inappropriately considers the clinoid segment as part of the cavernous one.

To improve the communication between endoscopic and open trained skull base surgeons, Alikhani et al. [2] correlated the endoscopic paraclival ICA to the transcranial segments of the vessel. Authors dissected two cadaveric specimens both endoscopically and transcranially with clipping the paraclival segment of the ICA, which corresponded to the lacerum and vertical cavernous segments of the ICA in the open surgical approach.

Additional interesting classification of the ICA in its relation to the quadrangular space and the contralateral ICA in the paraclival region was proposed by Dolci and his group [8]. In the 44 endoscopically dissected human cadaveric specimens, based on the trajectory of the ICA, they classified the intercarotid space into trapezoid, square and hourglass shapes, corresponding to the Type A (smallest), Type B (medium) and Type C (largest) quadrangular space respectively. Those spatial relations may be clinically important defining the best route the Meckel's cave.

Cappabianca et al. [4] on the contrary, evaluated the extracranial segment of the ICA in the $\mathrm{MRI}$ and CT examinations of 253 patients. Authors investigated the origin, development, course, persistence of embryonic vessels and anomalous origin of collateral branches. ICA kinking and /or coiling was found in $34 \%$ of cases. Reversed type location ( 2 cases), extracranial branching (1 case - ascending pharyngeal a.) and abnormal persistence of the proatlantal artery ( 3 cases) were rare entities. Both techniques showed similar accuracy in detecting those conditions.

On the side, but closely related to the ICA classifications is a discussion on an interesting but controversial term - carotid siphon, which was introduced by Moniz in 1927, published in his Lancet paper in 1933 [21], and in the monograph in 1934
[22]. As a forerunner of clinical use of cerebral vessels angiography, he made a name of the carotid siphon for a single anterior-facing ICA loop and the double siphon for two ICA loops (70\% of cases) in the lateral cerebral angiograms. Exact boundaries of the siphon were not mentioned in the text nor in the figures.

Moniz's conception was critically evaluated by Sanders-Taylor et al. [26]. Authors used Bouthillier's classification [3], modified by Depowell [7] to find out where the beginning and the end of the carotid siphon was intended to be in the original paper by Moniz. They confirmed lack of boundaries description both in the text and in the figures as well as an inconsistency in the figures captions. In the antero-posterior angiograms the petrous segment of the ICA was incorporated into the siphon. This would define the term carotid siphon as a radiological sign rather than a part of the ICA intracranial course. Over time the carotid siphon term gradually penetrated the anatomical research to be identified with a whole intracranial ICA [25]. Boundaries of the siphon were defined in several ways in the next papers - cavernous and intracranial ICA (C4-7) - [11], [27] and [23], cavernous and partially intracranial ICA - [13] - C4-6, [24] - C4-5 or the cavernous segment only (C4) - [19] and [15]. Sanders-Taylor et al. conclude that the carotid siphon, despite its vital historical significance, should not be further in use as it is inexact and creates miscommunication among researchers.

A useful teaching tool was presented in the recent review by Mele et al. [20]. Authors developed a new and freely available 3D interactive model of the internal carotid artery and the skull base, based on human neuroimages. The 3D-PDF file can be used on both Mac and Windows platforms and allows zoom, rotation, selective structure visualization and a predefined-sequence view. The artery can be view with its colored segments according to the classifications by Fisher [9], GiboRhoton [10], Bouthillier [3] and Labib [16] being an efficient study asset for student, resident and specialist training programs in the skull base surgery.

\section{CONCLUSIONS}

As described above, the ICA anatomy and topography still undergoes an extensive variety of research projects which is driven by the technical development in the diagnosis - from angiography though CT scanning and MRI scanning and surgical treatment - from open approaches, though the microscopic and endoscopic sphenoid sinus approaches to the advanced endovascular procedures. 


\section{COMPLIANCE WITH ETHICAL STANDARDS}

\section{Ethical approval}

All procedures performed in this study involving human specimens were in accordance with the ethical standards of institutional research committee and with the 1964 Helsinki declaration and its later amendments or comparable ethical standards.

\section{Informed consent}

Informed consent does not apply.

\section{AUTHORS' DECLARATION:}

Study Design: Rafał Chmielewski, Bogdan Ciszek; Data Collection: Rafał Chmielewski; Statistical Analysis: Rafał Chmielewski; Manuscript Preparation: Rafał Chmielewski. The Authors declare that there is no conflict of interest.

\section{REFERENCES}

1. Alfieri A, Jho HD. Endoscopic endonasal cavernous sinus surgery: an anatomic study. Neurosurgery 2001; $48: 827$.

2. Alikhani P, Sivakanthan S, Van Loveren H, Agazzi S. Paraclival or Cavernous Internal Carotid Artery: One Segment but Two Names. J Neurol Surgery, Part B Skull Base 2016; 77:304-307. https://doi.org/10.1055/s-0035-1568870.

3. Bouthillier a, van Loveren HR, Keller JT. Segments of the internal carotid artery: a new classification. Neurosurgery 1996; 38:425-432; discussion 432-433.

4. Cappabianca S, Somma F, Negro A, et al. Extracranial internal carotid artery: anatomical variations in asymptomatic patients. Surg Radiol Anat 2016; 38:893-902. https://doi.org/10.1007/s00276-016-1652-7.

5. Castelnuovo P, Dallan I, Tschabitscher M. Surgical Anatomy of the Internal Carotid Artery. Springer-Verlag, Berlin Heidelberg 2013.

6. Debrun G, Lacour P, Vinuela F, et al. Treatment of 54 traumatic carotid-cavernous fistulas. J Neurosurg 1981; 55:678-92. https://doi.org/10.3171/jns.1981.55.5.0678.

7. Depowell JJ, Froelich SC, Zimmer LA, et al. Segments of the internal carotid artery during endoscopic transnasal and open cranial approaches: Can a uniform nomenclature apply to both? World Neurosurg 2014; 82:S66-S71. https://doi. org/10.1016/j.wneu.2014.07.028.

8. Dolci RLL, Filho LFSD, Goulart CR, et al. Relation To the Quadrangular Space. 2017; 128:1-8. https://doi.org/10.3171/2016.10. JNS16381.

9. Fischer E. Die Lageabweichungen der vorderen hirnarterie im gefassbild. Zentralbl Neurochir 1938; 300-313.

10. Gibo H, Lenkey C, Rhoton AL. Microsurgical anatomy of the supraclinoid portion of the internal carotid artery. J Neurosurg 1981; 55:560-74. https://doi.org/10.3171/jns.1981.55.4.0560.

11. Herbert L, Abrams H. Angiography. J \& A Churchil, London 1961.

12. Herzallah IR, Casiano RR. Endoscopic endonasal study of the maxillary nerve: a new orientation. Am J Rhinol 2007; $21: 262-$ 270. https://doi.org/10.2500/ajr.2007.21.3084.

13. Huber P. Internal carotid artery. In: Publishers TM (ed) Cerebral Angiography, 2nd ed. New York 1982; 49-55.

14. noue T, Rhoton AL, Theele D, Barry ME. Surgical approaches to the cavernous sinus: A microsurgical study. Neurosurgery 1990; 26:903-932. https://doi.org/10.1227/00006123-199006000-00001.

15. Klosovskii B. Blood Circulation in the Brain. Israel Program for Scientific Translations, Jerusalem 1963.

16. Labib MA, Prevedello DM, Carrau R, et al. A road map to the internal carotid artery in expanded endoscopic endonasal approaches to the ventral cranial base. Neurosurgery 2014; 10:448-470. https://doi.org/10.1227/NEU.0000000000000362.

17. Lasjaunias P, Berenstein A. Arterial anatomy: Introduction. In: Surgical Neuroangiography: Functional Anatomy of Craniofacial Arteries. Springer-Verlag, Barlin 1987; 1-32 
18. van Loveren HR, Keller JT, el-Kalliny M, et al. The Dolenc technique for cavernous sinus exploration (cadaveric prosection). Technical note. J Neurosurg 1991; 74:837-44. https://doi.org/10.3171/jns.1991.74.5.0837.

19. Lozarthes G. Vascularisation of Circulation Cerebrales. Masson \& Cie Editeurs, Paris 1961.

20. Melé MV, Puigdellívol-Sánchez A, Mavar-Haramija M, et al. Review of the main surgical and angiographic-oriented classifications of the course of the internal carotid artery through a novel interactive 3D model. Neurosurg Rev. 2018. https://doi. org/10.1007/s10143-018-1012-7.

21. Moniz E. Cerebral angiography. Lancet 1933; 222:1144-1147.

22. Moniz E. Diagnostic des tumeurs cerebrales et epreuve de L'encephalographic arterielle. Mason et cie, Paris 1934.

23. Newton T, Potts D. Radiology of the skull and brain. In: Angiography. CV Mosby, St Louis 1974; 1202-1211.

24. Osborn A. Diagnostic Cerebral Angiography. Lippincot Williams \& Wilkins, New York 1999.

25. Rijshede J. Cerebral apoplexy; an arteriographical and clinical study of 100 cases. Acta Psychiatr Neurol Scand Suppl 1957; 118:1-210.

26. Sanders-Taylor C, Kurbanov A, Cebula H, et al. The carotid siphon: A historic radiographic sign, not an anatomic classification. World Neurosurg 2014; 82:423-427. https://doi.org/10.1016/j.wneu.2013.09.029.

27. Taveras J, Ernst H, Wood M. Diagnostic neuroradiology. In: Golden R (ed) Disease of the Central Nervous System. Williams \& Wilkins, Baltimore 1964; 490-494.

28. Willis T. The Anatomy od the Brain. USV Pharmaceutical Corp, Tuckahoe, NY 1971.

29. Ziyal IM, Ozgen T, Sekhar LN, et al. Proposed classification of segments of the internal carotid artery: anatomical study with angiographical interpretation. Neurol Med Chir (Tokyo) 2005; 45:184-190; discussion 190-191. https://doi.org/10.2176/ nmc.45.184.

Cite this article as: Chmielewski R, Ciszek B. Internal Carotid Artery Classification Systems. Pol J Aviat Med Bioeng Psychol 2018; 24(4): 27-35. DOI: 10.13174/pjambp.25.05.2020.03 